deal with nineteenth- or twentieth-century science, and most conform to the wish, expressed in the inaugural editorial, of providing information and interpretation that should interest practising scientists. Topics include interferon, Caenorhabditis elegans, gene mapping, Helicobacter pylori and the images of Barbara McClintock.

Consequently, this new journal can be welcomed as an important forum for contemporary debate. Within its first two volumes it has grown from two to four issues a year, in itself perhaps a reflection that the field is still growing.

W. F. Bynum is at the Wellcome Institute for the History of Medicine, 183 Euston Road, London NW1 2BE, UK.

\section{New shoots to replace the old?}

\section{Current Opinion in Plant Biology}

Editors Keith Roberts and Chris Somerville Current Biology Publications. 6/yr. Print

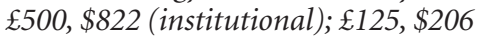

(personal). Online $\$ 227$ (personal only).

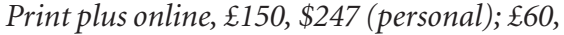
$\$ 90$ (student)

\section{Ortrun Mittelsten Scheid}

Current Opinion is the family name of quite a prolific clan. Last year, the parents at Current Biology Publications announced the birth of a new child, Plant Biology. Its bright green colour distinguishes it from its brothers and sisters on the shelf, but once opened it cannot conceal extensive family likenesses.

The concept of a bimonthly collection of invited, well-prepared reviews has proven very successful in other rapidly developing fields such as biotechnology, genetics and development, cell biology, immunology, neurobiology and others. But unavoidable overlap with other family members and with other review journals (related by the marriage between CBP and Elsevier) suggests a birth-control plan would now be in order.

The issues are grouped around growth and development (February), genome studies and molecular genetics (April), physiology and metabolism (June), plant microbe interaction (August), cell signalling and gene regulation (October), and cell biology (December). Each issue starts with Paper Alert, a personal but widely agreeable selection of important primary publications in all six fields, and Web Alert suggesting useful Internet sites. The editorial overview that follows usually comes closest to the family name and the intention expressed in the first volume - "to provide informed opinions about the burden of evidence and possible directions for new discoveries".

The reviews I read had much less of the opinion component. However, they were excellent summaries with informative introductions and a good compilation of basic as well as the most recent data, supported by suitable figures when necessary, and were followed by an extensive and ranked reference list. So far little use has been made of the ability to offer supplementary material such as video documentation via the publisher's home page, but this may change in the future. The concept of covering the same areas in the same month each year will render the journal an attractive source of information, also for readers who are not fond of systematic or computerbased literature search.

The price is high, but not unreasonable. Some institutions will not be able to add it to the budget without cancelling other subscriptions. But there is a good chance that this new member of the family will develop well, protected by its caring parents, the publishers, and its prominent godfathers

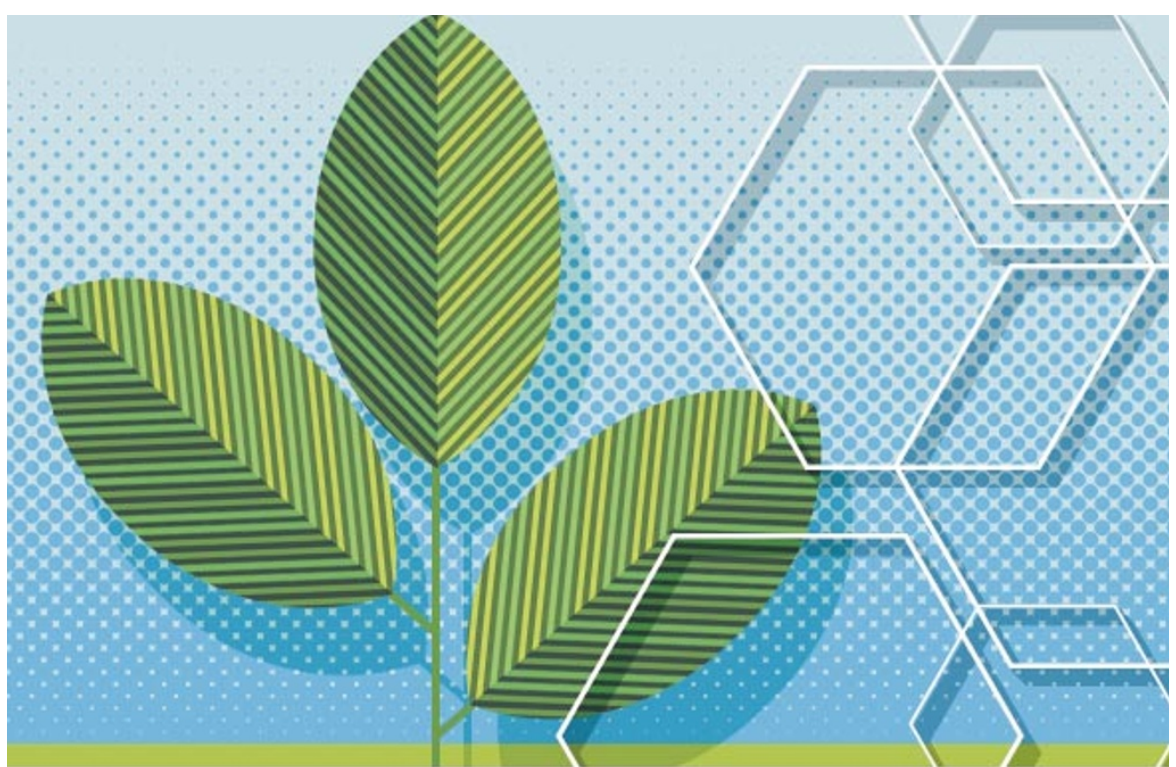

Roberts and Somerville. It is worth investing in its future, and going for a change of generation on the library shelves.

Ortrun Mittelsten Scheid is at the

Friedrich Miescher Institute, P.O. Box 2543,

CH 4002 Basel, Switzerland.

\section{Grains of wisdom unite two disciplines}

\section{Granular Matter}

Editors-in-chief R. P. Behringer and

H. J. Herrmann

Springer. 4/yr. \$332, DM498

\section{Dov Levine}

Granular materials such as sand are agglomerations of many macroscopic, hard, heavy particles, or grains. The grains don't deform appreciably, there are no randomizing effects of temperature and they dissipate energy in collisions and through friction.

Although granular materials may appear simple, the study of their physical properties is difficult: they are quintessential manybody systems, and knowing the interaction between two grains does not imply understanding of the system as a whole. They exhibit a wealth of fascinating behaviour, including novel pattern formation and interesting flow characteristics. Because of their strong dissipation, granular materials jam into static states whose properties are not amenable to standard statistical mechanics. The way force propagates in these states is different from any other system.

Engineers have long studied granular materials because of their importance in industry, while physicists have become interested more recently. The questions asked by the two communities are not always different, but the background assumed, the experimental tools used and the notation employed certainly make the papers look different. And, as is perhaps common in active interdisciplinary fields, there is a certain tension between the camps and the search for common ground is not always smooth.

Granular Matter was created to help find that common ground. Since there are so many journals in physics and engineering already, the editors' foremost aim is unification. This aims to be the journal of choice for the entire community, so that researchers of all backgrounds will be made aware of different approaches. This is a commendable idea for this exciting field. The first issues have had a nice collection of papers with a varied mix of authors, so Granular Matter is off to a good start. It is to be hoped that physics and engineering libraries alike will choose to add it to their shelves.

Dov Levine is in the Department of Physics,

Technion, 32000 Haifa, Israel. 